\title{
Will immunotherapy really change radiotherapy?
}

Citation for published version (APA):

Lambin, P., Lieverse, R., Baumann, M., \& Ebert, N. (2019). Will immunotherapy really change radiotherapy? Lancet oncology, 20(12), 1642-1644. https://doi.org/10.1016/S1470-2045(19)30682-5

Document status and date:

Published: 01/12/2019

DOI:

10.1016/S1470-2045(19)30682-5

Document Version:

Publisher's PDF, also known as Version of record

Document license:

Taverne

\section{Please check the document version of this publication:}

- A submitted manuscript is the version of the article upon submission and before peer-review. There can be important differences between the submitted version and the official published version of record.

People interested in the research are advised to contact the author for the final version of the publication, or visit the DOI to the publisher's website.

- The final author version and the galley proof are versions of the publication after peer review.

- The final published version features the final layout of the paper including the volume, issue and page numbers.

Link to publication

\footnotetext{
General rights rights.

- You may freely distribute the URL identifying the publication in the public portal. please follow below link for the End User Agreement:

www.umlib.nl/taverne-license

Take down policy

If you believe that this document breaches copyright please contact us at:

repository@maastrichtuniversity.nl

providing details and we will investigate your claim.
}

Copyright and moral rights for the publications made accessible in the public portal are retained by the authors and/or other copyright owners and it is a condition of accessing publications that users recognise and abide by the legal requirements associated with these

- Users may download and print one copy of any publication from the public portal for the purpose of private study or research.

- You may not further distribute the material or use it for any profit-making activity or commercial gain

If the publication is distributed under the terms of Article $25 \mathrm{fa}$ of the Dutch Copyright Act, indicated by the "Taverne" license above, 


\section{Perspectives}

\begin{tabular}{|llll|}
\hline & Staining & Interpretation & Positivity \\
\hline Pan cytokeratin & Cytoplasmic & Epithelial cells & + \\
Cytokeratin 20 & Cytoplasmic & $\begin{array}{l}\text { Colorectal, bile duct, pancreas, } \\
\text { gastric cells }\end{array}$ & +++ \\
CDX2 & Membranous or cytoplasmic & Colorectal cells & ++ \\
Cytokeratin 7 & Cytoplasmic & Negative in colonic cells & + \\
CD10 & Membranous or cytoplasmic & $\begin{array}{l}\text { Colon, pancreas, and prostate } \\
\text { carcinoma }\end{array}$ & ++ \\
Ki67 & Nuclear & Cell proliferation & ++ \\
HER2 & Membranous or cytoplasmic & Neoplastic progression & + \\
p53 & Nuclear or cytoplasmic & Tumour suppressor gene & ++ \\
+ indicates strong positivity, +++ very strong positivity, and - negativity. & + \\
\hline Table: Immunohistochemistry of the tumour cells & & \\
\hline
\end{tabular}

saccharum saturni) and water developed by the physician Antonio Guaineri, was used for many pathological conditions. $^{7}$

In the 16th century, the Swiss physician and alchemist Paracelsus strongly promoted the use of metals in the treatment of different diseases. Among these, mercury, antimony, gold, copper, and lead became the subject of interest and experimentation by the iatrochemical physicians. ${ }^{8}$
Although an external use of lead acetate, in particular was more common, there is clear evidence of the internal use of the compound in the writings of Renaissance and Modern age physicians. ${ }^{9}$ Lead acetate was used to stop diarrhoea and gut haemorrhages. In fact, sugar of lead acetate and copper, considered astringent substances, were used orally in the 16 th century medicine and later, in particular by followers of Paracelsus, to cure the intestinal bleeding and diarrhoea. ${ }^{10}$

It is possible that Luigi Carafa, who had an advanced stage of the cancer that is likely to have caused melaena, was treated with a similar potion, which explains the extraordinaryly unique preservation of the intestinal tissues and the perfect histological picture of the colon adenocarcinoma. This case represents one of those very rare instances in which direct evidence of ancient medicine can be gained from accurate ancient body examination.

\section{*Antonio Fornaciari, Raffaele Gaeta, Silvio Chericoni, Fabio Stefanelli, Antonio Giuseppe Naccarato, Maura Castagna, Riccardo Lencioni, Valentina Giuffra, Gino Fornaciari}

\section{(1) Spotlight Will immunotherapy really change radiotherapy?}

PL and RL thank financial support from European Research Council advanced grant (ERC-ADG-2015,

number 694812) and the European Program H2020-2017 (ImmunoSABR number 733008). PL and RL declare no competing interests.

For more on the preclinical work combining immunotherapy and standard of care see

Nat Commun 2017; 8: 15618 For more on the phase 3 trial see N EnglJ Med 2018; 379: 2342-50

For more on treatment approaches with

immunocytokines see Clin Cancer Res 2015; 21: 1151-60

For more on patient selection for radioimmunotherapy see Series Lancet Oncol 2019; 20: e452-63
Opening opinion: Yes

\section{Philippe Lambin, Relinde Lieverse}

The M-Lab \& D-Lab, Department of Precision Medicine, GROW-School for Oncology and Developmental Biology, Maastricht University, Maastricht, Netherlands

philippe.lambin@maastrichtuniversity.nl

Cancer is a systemic disease and more than 90\% of patients with cancer are dying of metastasis while radiotherapy is being used as the loco-regional treatment. This issue has been the formidable challenge of radiotherapy for more than a century, having an effect on locoregional control, but no or limited effect on overall survival. The high-quality translational work and a randomised phase 3 trial in non-small cell lung cancer comparing immunotherapy with standard of care have been game changers. Durvalumab significantly prolonged overall survival compared with placebo (stratified hazard ratio for death $0.68 ; p=0.0025$ ).

So, is this the definitive solution? Should we just use this unchanged chemoradiotherapy protocol followed by the standard checkpoint inhibitors a few weeks later? My answer to this last question is no, because I believe that immunotherapy will really change radiation oncology Immunotherapy is a paradigm changer in oncology, although the long-term cure is still unacceptably low. Combining immunotherapy with a proven therapeutic approach is obvious and radiotherapy looks to be ideally suited to this role for several reasons: primarily because of its known safety profile, but also its capacity to mediate robust immunostimulatory effects, which might be able to aid immunotherapy in achieving systemic tumour control.

There are several arguments to investigate fundamental changes of current radiation oncology practice. Nowadays, it is assumed that radiotherapy is, in the long term, most effective when it causes tumour-targeting immune responses. As a consequence, radiotherapy could be administered in doses and schedules that stimulate anticancer immunity rather than kill cancer cells through DNA damage. But we know that the combination of radiotherapy with immunotherapy has a systemic effect, improving the overall survival in non-small-cell lung cancer (PACIFIC trial).

Strong (pre)clinical evidence suggests that key effectors of immunotherapy are CD8-positive lymphocytes. Irradiation of large blood vessels, the heart, and lymphoid 
organs (including nodes, spleen, bone marrow, and thymus) can cause lymphopenia. We propose that, whenever possible, lymphocytes should be spared (in a process we named Lymphocytes-Sparing Radiotherapy; eg, large vessels should be an organ at risk). Draining lymph nodes are the main sites of T-cell cross-priming by dendritic cells crucial for the initiation of antitumour immune responses. Therefore, prophylactic irradiation of the nodes should be avoided. Some trials have shown that avoiding the irradiation of PET negative nodes does not worsen the results.

Typically, the dose even in routine clinical practice for curative treatment is just below the maximum tolerated dose to maximise the direct killing effect of radiation through DNA damage. When combined with immunotherapy, the objective is no longer to maximise DNA damage of the tumour, but to maximise the synergistic combination with immunotherapy. This approach gives us opportunities to find the optimal therapeutic window for each disease. Some data, for example, show that radiotherapy appears to sensitise certain types of antigen negative tumours and that fractionation can have a negative effect by killing intratumoural CD8-positive cells. With immunotherapy combination, there is a case for hypofractionation with immunogenic dose per fraction around $8 \mathrm{~Gy}$.

In conventional radiotherapy, the whole tumour is irradiated with different margins for microscopic disease uncertainties. Although some clinical and preclinical studies show that non-irradiated tumours can be cured by abscopal effect and that partial cancer irradiation can also have a curative effect. Therefore, these textbook concepts might have to be revisited, particularly in the case of reirradiation.

Some arguments are more strategic. Typically, in standard therapies, the care giver is lagging behind the events: a treatment is started when tumour recurs. The effect with immunotherapy is different: immunotherapy has an anticancer immune response to yield a long-term response beyond treatment discontinuation (the so-called vaccination effect). This effect is due to memory cells that can be reactivated and this translates to a tail seen at the end of the survival curve.

There are other immunotherapy approaches that work better than checkpoint inhibitors with radiotherapy: it is clear that, in monotherapy, the checkpoint inhibitors are the leading immunotherapeutics in oncology. However, this success as monotherapy does not imply that these checkpoint inhibitors would be the best option in combination with radiotherapy. For example, in our preclinical and clinical work (NCT02086721 and NCT03705403) with immunocytokines, we found that a press-the-accelerator approach rather than a releasethe-break approach has a higher synergistic effect with radiotherapy, implying that checkpoint inhibitions are not necessarily the optimal choice in combination treatment.

Many new immunotherapeutics will come into the clinic. It will be crucial to develop biomarkers specific for combination of immunotherapy and radiotherapy to select the right patient population and avoid unnecessary toxicity and cost.

In preclinical studies, the immune system has been shown to participate in the therapeutic effect of radiotherapy, as well as being instrumental to the acute and chronic toxicities of radiotherapy. We need to do more mechanistic research: we cannot delegate this type of research to other specialists. The radiotherapy community has to take on its responsibilities. Finally, immunotherapy should be part of the basic curriculum of a young radiation oncologist.

In summary, radiation oncology is at an important moment of its life time; we should embrace the opportunity rather than resist it for the greater benefit of science and our patients. The new framework will be redesigning the way radiotherapy is delivered to interact most optimally with immunotherapy rather than directly killing as many cells as possible with radiation.

\section{Counter opinion: Not yet \\ Michael Baumann, Nadja Ebert}

German Cancer Research Center, Heidelberg and

OncoRay-National Center for Radiation Research in Oncology,

Dresden, Germany

michael.baumann@dkfz-heidelberg.de

During the past 5 years, immunotherapy has become an established anticancer treatment. Immune checkpoint inhibitors have rapidly shown effectiveness in many, but not all, types of tumours. Typically, remission in metastatic disease occurs in about $20 \%$ of patients with some responses being durable and potentially even curative. Although these results are impressive, the majority of tumours so far do not respond to immunotherapy and side-effects are not uncommon. Additionally, immunotherapy is, at present, very expensive and not available to many patients with cancer worldwide. Further research is needed to better understand the interactions of the immune system with tumours, mechanisms of resistance against immunotherapy, and predictive biomarkers. New and more efficacious immunotherapy strategies need to be developed. Finally, immunotherapy needs to be efficiently integrated with other current anticancer treatments, including radiotherapy.

It is well recognised that radiation can evoke stimulatory or suppressive immune effects. The biological mechanisms underlying these effects are not fully understood yet. In preclinical models, radiation-associated immune stimulatory effects on tumours are variable, depending on the tumour model, and radiotherapy dose and fractionation. The combination of checkpoint inhibitors
MB attended an advisory board meeting of Merck KGaA, for which the University of Dresden received a travel grant; received funding from Teutopharma $\mathrm{GmbH}$, Iron Beam Applications, Bayer, Merck KGaA, and Medipan $\mathrm{GmbH}$; is on the supervisory boards of HI-STEM gGmbH; and is the former chair of OncoRay and present CEO and Scientific Chair of the German Cancer Research Center, in this capacity he has been responsible for collaborations and contracts with many companies and institutions. NE was co-principal investigator for a research project funded by Merck KGaA to the University of Dresden. None of the funding sources were involved in this work.

For more on radiation effects in the immune system see Nature Rev Clin Oncol 2017; 14: 365-79.

For more on the secondary analysis of KEYNOTE-001 trial see Articles Lancet Oncol 2017; 18: 895-903

For more on the PACIFIC trial see N Engl J Med 2017; 377: 1919-29 For more on the PEMBRO-TR trial see JAMA Oncol 2019; 5: 1276-82 


\section{Perspectives}

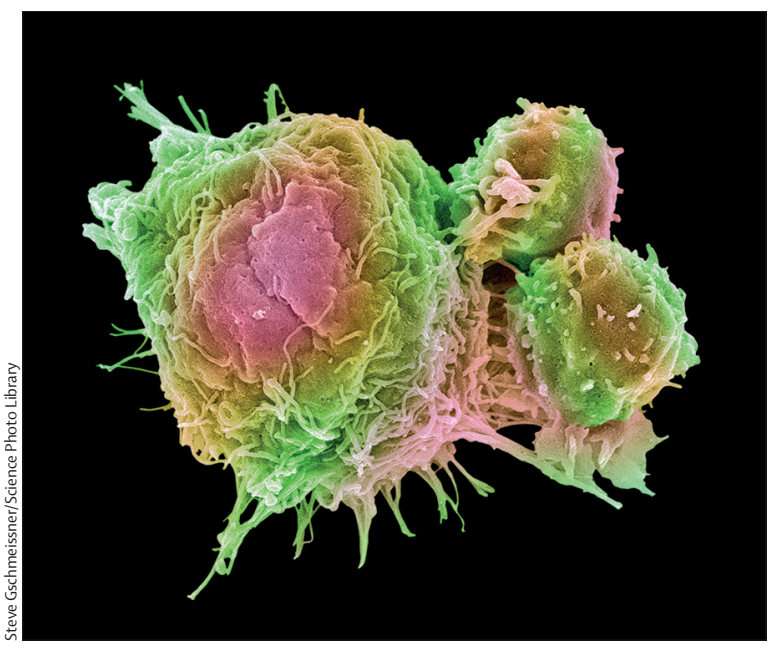

with radiotherapy to further increase tumour response has gained substantial interest. This approach is spurred by preclinical and clinical reports showing remarkable responses or abscopal effects (response also of nonirradiated lesions) when checkpoint inhibitors are applied with or after radiotherapy in some cancers.

The notion that immunotherapy is changing the fundamentals and clinical practice of radiotherapy, however, is, to say the least, premature and cannot be derived from available data. True improvements of radiotherapy aim to widen the therapeutic window between the chance to eradicate the tumour (or metastases) and the risk of inducing normal tissue damage. A fundamental change of radiotherapy, for example, would be if immunotherapy allowed radiation oncologists to reduce the radiation dose to the tumour substantially without decreasing the chance of local control. In this case, healthy tissues could be better spared from the detrimental effects of radiation if the immune stimulatory effects were restricted to the tumour tissue. Immunotherapy could also widen the therapeutic window if healthy tissues were spared through reduced margin around the tumour, or if abscopal effects could be enhanced substantially. These effects have not been tested or shown by the seminal studies reported so far. For example, a secondary analysis of the KEYNOTE-001 phase 1 trial evaluated patients who received radiotherapy (not part of the trial) for locally advanced or metastatic non-small-cell lung cancer (NSCLC) before receiving pembrolizumab. Progression-free, and overall survival were significantly longer in irradiated patients, but treatment-related lung toxicity appeared to be increased; however, the study was not sufficiently powered to answer this question. Selection bias for more indolent disease in the irradiated group cannot be excluded as the time interval between initial diagnosis and receipt of pembrolizumab was significantly longer in patients after radiotherapy than for patients who had not previously had radiotherapy. The randomised PACIFIC phase 3 trial showed significantly longer progressionfree and overall survival when durvalumab was given after standard platinum-based radiochemotherapy in stage III unresectable NSCLC. Pneumonitis was higher after checkpoint inhibition; however, the proportion of grade 3 and 4 pneumonitis events was similar in both groups. The randomised PEMBRO-RT phase 2 trial showed that stereotactic body radiotherapy delivered to a single tumour site enhanced the effect of pembrolizumab in non-irradiated lesions of metastatic NSCLC, but the results did not meet the preset endpoint criteria for meaningful clinical benefit. Pneumonia occurred more often in the experimental group than in the control group. Post-hoc hypothesis generating analysis suggested immune-stimulating effects of radiation in PD-L1 negative tumours. Probably the most important result of these trials is that immunotherapy is also efficacious in patients who have previously been treated with radiotherapy. However, as standard radiotherapy schedules were applied, the studies do not answer to the question of whether radiotherapy can be changed by immunotherapy. The study designs also do not allow assessment of whether the effects are synergistic and whether the therapeutic window is widened. It also remains unclear whether immunotherapy might be equally effective when delayed and restricted to tumour progression after radiotherapy.

Taken together, preclinical and clinical studies so far do not provide evidence that the fundamental concepts of radiotherapy will be changed by immunotherapy. Better understanding of the interactions of radiotherapy with immune responses and immunotherapy remains an important challenge for future research. In our view, changes in clinical practice for radiotherapy are only justified in the context of well designed clinical trials. 